University of Nebraska - Lincoln

DigitalCommons@University of Nebraska - Lincoln

\title{
Prediction of retail product weight and percentage using ultrasound and carcass measurements in beef cattle
}

\author{
S. P. Greiner \\ lowa State University, sgreiner@vt.edu \\ G. H. Rouse \\ lowa State University \\ D. E. Wilson \\ lowa State University \\ L. V. Cundiff \\ U.S. Meat Animal Research Center, Larry.Cundiff@ars.usda.gov \\ T. L. Wheeler \\ U.S. Meat Animal Research Center, tommy.wheeler@ars.usda.gov
}

Follow this and additional works at: https://digitalcommons.unl.edu/hruskareports

Greiner, S. P.; Rouse, G. H.; Wilson, D. E.; Cundiff, L. V.; and Wheeler, T. L., "Prediction of retail product weight and percentage using ultrasound and carcass measurements in beef cattle" (2003). Roman $L$. Hruska U.S. Meat Animal Research Center. 366.

https://digitalcommons.unl.edu/hruskareports/366

This Article is brought to you for free and open access by the U.S. Department of Agriculture: Agricultural Research Service, Lincoln, Nebraska at DigitalCommons@University of Nebraska - Lincoln. It has been accepted for inclusion in Roman L. Hruska U.S. Meat Animal Research Center by an authorized administrator of DigitalCommons@University of Nebraska - Lincoln. 


\title{
Prediction of retail product weight and percentage using ultrasound and carcass measurements in beef cattle
}

\author{
S. P. Greiner*1, G. H. Rouse*, D. E. Wilson*, L. V. Cundiff $†$, and T. L. Wheeler $\dagger$ \\ *Department of Animal Science, Iowa State University, Ames 50011 \\ and $†$ Roman L. Hruska U.S. Meat Animal Research Center, USDA, ARS, Clay Center, NE 68933
}

\begin{abstract}
Data from 534 steers representing six sire breed groups were used to develop live animal ultrasound prediction equations for weight and percentage of retail product. Steers were ultrasonically measured for 12th-rib fat thickness (UFAT), rump fat thickness (URPFAT), longissimus muscle area (ULMA), and body wall thickness (UBDWALL) within $5 \mathrm{~d}$ before slaughter. Carcass measurements included in USDA yield grade (YG) and quality grade calculations were obtained. Carcasses were fabricated into boneless, totally trimmed retail products. Regression equations to predict weight and percentage of retail product were developed using either live animal or carcass traits as independent variables. Most of the variation in weight of retail product was accounted for by live weight (FWT) and carcass weight with $R^{2}$ values of 0.66 and 0.69 , respectively. Fat measurements accounted for the

largest portion of the variation in percentage of retail product when used as single predictors $\left(\mathrm{R}^{2}=0.54,0.44\right.$, 0.23 , and 0.54 for UFAT, URPFAT, UBDWALL, and carcass fat, respectively). Final models $(P<0.10)$ using live animal variables included FWT, UFAT, ULMA, and URPFAT for retail product weight $\left(\mathrm{R}^{2}=0.84\right)$ and UFAT, URPFAT, ULMA, UBDWALL, and FWT for retail product percentage $\left(R^{2}=0.61\right)$. Comparatively, equations using $Y G$ variables resulted in $R^{2}$ values of 0.86 and 0.65 for weight and percentage of retail product, respectively. Results indicate that live animal equations using ultrasound measurements are similar in accuracy to carcass measurements for predicting beef carcass composition, and alternative ultrasound measurements of rump fat and body wall thickness enhance the predictive capability of live animal-based equations for retail yield.
\end{abstract}

Key Words: Beef, Carcasses, Meat Yield, Prediction, Ultrasound

(C2003 American Society of Animal Science. All rights reserved.

J. Anim. Sci. 2003. 81:1736-1742

\section{Introduction}

Real-time ultrasound has been shown to be an accurate predictor of carcass 12 th-rib fat thickness and longissimus muscle area in beef cattle (Robinson et al., 1992; Duello, 1993). Ultrasound technology has also been used to predict beef carcass retail yield. In a study using 180 steers representing 11 sire-breed groups, Hamlin et al. (1995) reported that ultrasonic measurements of fat thickness and longissimus muscle area, when combined with live weight, accounted for 61 to $64 \%$ of the variation in percentage of retail product. To aid in the prediction of beef carcass composition, alternative ultrasonic sites to 12 th-rib fat thickness and longissimus muscle area have been investigated. Wal-

\footnotetext{
${ }^{1}$ Correspondence and present address: Department of Animal and Poultry Sciences, Virginia Tech, 366 Litton-Reaves Hall, Blacksburg 24061 (phone: 540-231-9159; fax: 540-231-3713; E-mail: sgreiner @vt.edu).

Received June 11, 2002.

Accepted March 20, 2003.
}

lace et al. (1977) reported a correlation of -0.53 between ultrasonic rump fat thickness and retail yield, and Miller et al. (1988) showed rump fat thickness could account for a large portion of the variation in carcass fat. Williams et al. (1997) showed the addition of rump fat to live animal predictors of yield grade components increased the $\mathrm{R}^{2}$ value 0.14 for predicting percentage of retail product. In contrast, Realini et al. (2001) reported rump fat thickness to explain little additional variation in carcass yield when used with ultrasonic 12th-rib fat thickness and longissimus muscle area. Furthermore, Cross et al. (1973) reported correlations of 0.41 and -0.61 between carcass body wall thickness with weight and percentage of retail cuts, respectively. Perkins et al. (1992) found that ultrasound body wall thickness is related to carcass fat and lean parameters. Therefore, the objective of this study was to examine the efficacy of using traditional ultrasonic measures of 12th-rib fat and longissimus muscle area, along with ultrasonic rump fat and body wall thickness, to predict weight and percentage of totally trimmed beef carcass retail product in a large number of steers that had considerable variation in carcass composition. 


\section{Materials and Methods}

This study was conducted in cooperation with the Roman L. Hruska U.S. Meat Animal Research Center (MARC), Clay Center, NE. Five hundred thirty-four calf-fed steers from the 1993 (year $1, \mathrm{n}=282$ ) and 1994 (year 2, $\mathrm{n}=252$ ) calf crops of Cycle $\mathrm{V}$ of the Germplasm Evaluation (GPE) program were used (Wheeler et al., 2001). Cycle V crossbred calves were produced by mating Hereford, Angus, and MARC III ( $1 / 4$ Red Poll, $1 / 4$ Hereford, 1/4 Pinzgauer, 1/4 Angus) dams to Hereford, Angus, Tuli, Boran, Belgian Blue, and Brahman bulls. Wheeler et al. (2001) has a detailed description of the sources of the experimental animals and their management, harvest, and processing.

Each year, within $5 \mathrm{~d}$ before harvest, steers were measured ultrasonically by the same Beef Improvement Federation (BIF, 1997) certified technician for fat thickness between the 12th and 13th ribs, $3 / 4$ the length ventrally over the longissimus (UFAT), and for longissimus muscle area between the 12th and 13th ribs (ULMA). Images were also collected for rump fat thickness at the junction of the biceps femoris and gluteus medius between the ischium and illium, and parallel to the vertebral column (URPFAT). Body wall thickness at the 12th-13th rib interface was collected perpendicular to the external body surface at a distance of $4 \mathrm{~cm}$ from the ventral tip of the longissimus muscle (UBDWALL). Images were taken with an Aloka 500V real-time ultrasound machine (Corometrics Medical Systems, Wallingford, CT) equipped with a $17.2-\mathrm{cm}$, $3.5-\mathrm{MHz}$ linear transducer. To ensure proper contact between the ultrasound transducer and animal, the transducer was fitted with a Superflab (Mick RadioNuclear Instruments, Inc., Bronx, NY) guide for UFAT and ULMA image collection. In the area to be scanned, hair was clipped, thoroughly curried, and cleaned before image collection. Vegetable oil was used as a couplant to obtain adequate acoustic contact. Once a suitable image had been obtained, the image was digitized and stored on a personal computer with a video frame grabber. Only one image per animal was stored for each ultrasound trait. Images were interpreted using software developed at Iowa State University. A final live weight (FWT) was also obtained.

At $36 \mathrm{~h}$ postmortem, the right side of each carcass was transported to MARC for fabrication into boneless, totally trimmed retail product. Sides were cut into wholesale and subprimal cuts were trimmed to $0 \mathrm{~cm}$ of fat, lean trim, fat trim, and bone as described by Wheeler et al. (1997). Chemical fat content was used to adjust the lean trim to $20 \%$ fat. Weights of boneless, totally trimmed retail cuts and $20 \%$ fat lean trim were summed to give retail product weight (KGRPRD). The percentage of retail product (PRPRD) was calculated by dividing retail product weight by the sum of the parts (retail product weight + fat trim weight + bone weight $) \times 100$. The sum of parts was used rather than hot carcass weight $(\mathbf{H C W})$ to avoid bias in yield due to the variable amount of shrink that occurred over the 2wk period required for complete dissection of all carcass sides.

Statistical analyses were conducted using SAS (SAS Inst., Inc., Cary, NC). Pearson product-moment correlations were estimated between live animal and carcass traits with weight and percentage of retail product. Prediction product moment equations were developed by stepwise regression procedures using either live animal or carcass traits as independent variables. Independent variables had to be significant $(P<0.10)$ to remain in models. Equations were evaluated with respect to $\mathrm{R}^{2}$, root mean square error (RMSE), and $\mathrm{C}_{\mathrm{p}}$ as described by Mallows' statistic (1973). For models with a close fit, $\mathrm{C}_{\mathrm{p}}$ approaches the number of predictor variables (MacNeil, 1983). Genetic and environmental effects were not considered in the modeling process.

Prediction equations using carcass measurements were developed as a comparison to equations developed using live animal measurements. Measurements of adjusted fat thickness (ACFAT), longissimus muscle area (CLMA), estimated percentage of kidney, pelvic, and heart fat (CKPH), HCW, and marbling score (MARB) were used to develop carcass prediction equations.

\section{Results and Discussion}

Descriptions of the acronyms assigned to variables are presented in Table 1. Means, SD, and ranges for live animal and carcass traits are reported in Table 2. The sire breeds used in the GPE study resulted in a large amount of variation in carcass cutability, with PRPRD ranging from 53.7 to $75.8 \%$ and calculated USDA yield grade ranging from 1.2 to more than 5.9. Average HCW, ACFAT, and CLMA for carcasses included in this study were $343 \mathrm{~kg}, 1.01 \mathrm{~cm}$, and 78.1 $\mathrm{cm}^{2}$, respectively.

Presented in Table 3 are simple correlation coefficients for carcass and live animal traits with weight and percentage of retail product. Weight and muscle variables had the strongest relationships with KGRPRD, ranging from 0.61 for ULMA to 0.83 for HCW. Carcass variables had higher correlations with KGRPRD than the corresponding traits measured in the live animal ( 0.83 vs. 0.81 for weight, and 0.68 vs. 0.61 for longissimus muscle area). In contrast, when retail product was expressed as a percentage, variables describing weight had negative correlations, whereas those describing longissimus muscle area had positive correlation estimates. Measurements of 12 th-rib fat thickness had small, but significant negative relationships with KGRPRD ( -0.12 and -0.10 for ACFAT and UFAT, respectively); however, correlations between URPFAT and UBDWALL with KGRPRD were either small $(\mathrm{r}=0.11)$ or nonsignificant $(P>0.10)$.

Measures of fat (ACFAT, CKPH, UFAT, URPFAT, UBDWALL) had negative correlations with retail product percentage. The highest correlation was found for UFAT $(r=-0.74)$, which is stronger than the correla- 
Table 1. Description of acronyms

\begin{tabular}{ll}
\hline \hline Acronym & \\
\hline FWT & Final unshrunk weight, $\mathrm{kg}$ \\
UFAT & Ultrasound 12th-rib fat thickness, cm \\
ULMA & Ultrasound longissimus muscle area, $\mathrm{cm}^{2}$ \\
URPFAT & Ultrasound rump fat thickness, cm \\
UBDWALL & Ultrasound body wall thickness, cm \\
HCW & Hot carcass weight, kg \\
ACFAT & Adjusted carcass 12th-rib fat thickness, cm \\
CLMA & Carcass longissimus muscle area, cm ${ }^{2}$ \\
CKPH & Estimated kidney, pelvic, and heart fat, $\%$ \\
MARB & Marbling score, $300=$ Traces \\
KGRPRD, $400=$ Slight \\
KGR, $500=$ Small $^{0}, 600=$ Modest $^{0}, 700=$ Moderate $^{0}$ \\
PRPRD & Weight of totally trimmed, boneless retail product and lean trim adjusted to $20 \%$ \\
& fat from one carcass side, kg \\
& Totally trimmed, boneless retail product and lean trim adjusted to $20 \%$ fat \\
\hline
\end{tabular}

tions reported for actual and adjusted carcass fat thickness ( -0.68 and -0.73 , respectively). The higher correlation for ACFAT vs. actual carcass fat thickness reflects necessary adjustments made for uneven distribution of fat and disruption of the fat layer over the longissimus muscle during hide removal. Measurements of fat had stronger correlations with retail product percentage than measurements of muscle. Alternative ultrasonic fat measurement sites (URPFAT and UBDWALL) were also highly related to PRPRD. Williams et al. (1997) reported URPFAT accounted for a larger portion of the variation in PRPRD than UFAT. Others have shown rump fat thickness to be useful in predicting percentage of carcass fat (Wallace et al., 1977; Miller et al., 1988). In the present study, UFAT had the strongest relationship with PRPRD. Cross et al. (1973) reported a correlation of -0.61 between carcass body wall thickness and percentage of retail cuts. A similar correlation of -0.48 was found in this study when body wall thickness was estimated ultrasonically.
Several researchers have developed equations for predicting weight and percentage of retail product using carcass and live animal (Crouse and Dikeman, 1976; Herring et al., 1994; Williams et al., 1997). Regression equations for predicting weight and percentage of retail product from live animal measurements are presented in Table 4. Most of the variation in PRPRD was explained by UFAT with an $R^{2}$ value of 0.54 when fit alone (data not shown). Ultrasonic rump fat was the second variable to enter into the model using stepwise regression $\left(R^{2}=0.44\right.$ alone), and together UFAT and URPFAT accounted for $58 \%$ of the variation in PRPRD (Equation 1). Variability in KGRPRD was largely attributed to differences in FWT, resulting in an $\mathrm{R}^{2}$ value of 0.66 when used as a single predictor (data not shown).

Researchers have found 12th-rib fat thickness to be the best measurement for predicting beef carcass retail product yield (Crouse and Dikeman, 1976; Abraham et al., 1980). In addition, other measurement sites for fat

Table 2. Simple statistics for live animal and carcass traits ${ }^{\mathrm{a}}$

\begin{tabular}{lcccc}
\hline \hline Trait & Mean & SD & Minimum & Maximum \\
\hline Live & & & & \\
FWT, kg & 555.0 & 63.6 & 354.3 & 760.8 \\
UFAT, cm & 1.02 & 0.35 & 0.23 & 2.06 \\
ULMA, cm ${ }^{2}$ & 78.8 & 7.6 & 59.3 & 104.0 \\
URPFAT, cm & 1.09 & 0.32 & 0.30 & 2.29 \\
UBDWALL, cm & 5.36 & 0.82 & 3.34 & 8.43 \\
Carcass & & & & 462.9 \\
HCW, kg & 342.5 & 41.9 & 214.4 & 2.79 \\
Actual fat thickness, cm & 1.09 & 0.44 & 0.25 & 2.54 \\
ACFAT, cm & 1.01 & 0.42 & 0.25 & 111.6 \\
CLMA, cm & 78.1 & 8.7 & 43.2 & 5.00 \\
CKPH, \% & 2.96 & 0.61 & 1.00 & 6.11 \\
USDA yield grade & 3.08 & 0.73 & 1.25 & 770.0 \\
MARB & 503.8 & 62.0 & 350.0 & 220.5 \\
Side weight, kg & 161.5 & 19.9 & 103.1 & 144.1 \\
KGRPRD, kg & 103.5 & 12.8 & 72.2 & 75.8 \\
PRPRD, \% & 64.2 & 4.2 & 53.7 & \\
\hline
\end{tabular}

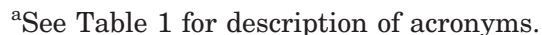

${ }^{\mathrm{b}} \mathrm{Sum}$ of retail product, fat trim, and bone. 
Table 3. Simple correlations of traits with weight and percentage of retail product ${ }^{\mathrm{a}}$

\begin{tabular}{lcr}
\hline \hline Trait & KGRPRD & PRPRD \\
\hline FWT & $0.81^{\mathrm{b}}$ & -0.26 \\
UFAT & -0.10 & -0.74 \\
ULMA & 0.61 & 0.17 \\
URPFAT & 0.03 & -0.66 \\
UBDWALL & 0.11 & -0.48 \\
HT & 0.63 & -0.11 \\
HCW & 0.83 & -0.26 \\
Actual fat thickness & -0.08 & -0.68 \\
ACFAT & -0.12 & -0.73 \\
CLMA & 0.68 & 0.31 \\
CKPH & 0.05 & -0.40 \\
USDA yield grade & -0.06 & -0.79 \\
MARB & -0.04 & -0.52 \\
\hline
\end{tabular}

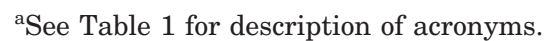

${ }^{\mathrm{b}}$ Correlation coefficients with absolute values $\geq 0.08$ are different from zero $(P<0.10)$.

in both the live animal and carcass have been shown to be useful for predicting composition in beef cattle (Wallace et al., 1977; Williams et al., 1997). In the present study, both UFAT and URPFAT were significant variables in equations when retail product was expressed on a weight or percentage basis. Ultrasonic 12th-rib fat thickness was the first fat measurement variable to enter into the stepwise regression modeling process for prediction of both PRPRD and KGRPRD. This is in contrast to Williams et al. (1997), who reported rump fat to be superior to ultrasonic 12th-rib fat in predicting retail yield from live animal measures. In the present study, URPFAT accounted for an additional $4 \%$ of the variation in PRPRD when used with UFAT (Equation 1). Realini et al. (2001) reported similar $\mathrm{R}^{2}$ values for live-animal prediction equations developed with and without ultrasound rump fat thickness. In the present study, retail product was trimmed to 0 $\mathrm{cm}$ compared to a fat trim level of $0.32 \mathrm{~cm}$ for Realini et al. (2001). Rump fat may be most useful in accounting for differences in retail product percentage that result from differences in total fat as trim level is reduced.
Alone, UFAT and URPFAT explained less than 5\% of the variation in retail product weight. However, inclusion of UFAT with live weight (Equation 7) increased the $R^{2}$ value from 0.66 to 0.78 compared to using live weight alone to predict KGRPRD. Although a significant $(P<0.10)$ variable for prediction of retail product weight (Equation 9), URPFAT explained $<1 \%$ of the additional variation after FWT, UFAT, and ULMA had been included in the model.

Carcass body wall thickness has been reported to be related to both percentage and weight of retail cuts (Brungardt and Bray, 1963; Cross et al., 1973). In the present study, UBDWALL was a significant variable in prediction of PRPRD, but not KGRPRD. However, UBDWALL only improved the $R^{2}$ from 0.60 to 0.61 when included with UFAT, URPFAT, and ULMA to predict PRPRD (Equation 2 vs. 5). This is in agreement with Perkins et al. (1992), who reported ultrasonic body wall thickness added little predictive power for retail yield beyond 12th-rib fat thickness and longissimus muscle. Furthermore, Abraham et al. (1980) found body wall thickness measured $10.2 \mathrm{~cm}$ from the lateral end of the longissimus muscle to be a significant variable for prediction of percentage of retail cuts, but concluded improvement in cutability equations when added to yield grade variables did not warrant its inclusion.

Ultrasound longissimus muscle area was a significant variable in equations to predict both weight and percentage of retail product. Addition of ULMA to UFAT and URPFAT explained an additional $1.4 \%$ of the variation in PRPRD (Equation 1 vs. 2), and an additional $4.3 \%$ of the variation for KGRPRD when included with FWT and UFAT (Equation 7 vs. 8). Hamlin et al. (1995) reported longissimus muscle area measured with ultrasound to offer little improvement in $\mathrm{R}^{2}$ value ( 0 to 0.03$)$ in models for predicting percentage of retail product after inclusion of a fat and weight measurement. Similarly, Herring et al. (1994) and Wallace et al. (1977) reported that neither ULMA nor CLMA improved prediction equations for weight or percentage of retail product. Corresponding to the results

Table 4. Equations for predicting weight and percentage of retail product from live animal measurements ${ }^{\mathrm{a}}$

\begin{tabular}{|c|c|c|c|c|c|c|c|c|c|}
\hline $\begin{array}{l}\text { Dependent variable } \\
\text { and equation }\end{array}$ & $\mathrm{R}^{2}$ & RMSE & $\mathrm{C}_{\mathrm{p}}$ & \multicolumn{6}{|c|}{ Partial regression coefficients } \\
\hline \multicolumn{10}{|l|}{ PRPRD } \\
\hline 1 & 0.58 & 2.74 & 39.78 & 74.92 & -6.486 & -3.722 & - & - & - \\
\hline 2 & 0.60 & 2.70 & 23.80 & 69.78 & -6.283 & -3.841 & 0.064 & - & - \\
\hline 3 & 0.57 & 2.79 & 63.67 & 70.41 & -8.227 & - & 0.093 & - & -0.009 \\
\hline 6 & 0.61 & 2.65 & 6.00 & 71.71 & -5.201 & -3.423 & 0.107 & -0.744 & -0.005 \\
\hline \multicolumn{10}{|l|}{ KGRPRD } \\
\hline 7 & 0.78 & 5.98 & 163.11 & 14.25 & -13.568 & - & - & - & 0.186 \\
\hline 8 & 0.83 & 5.34 & 24.64 & -6.37 & -11.514 & - & 0.403 & - & 0.162 \\
\hline 9 & 0.84 & 5.24 & 5.00 & -6.01 & -8.718 & -4.811 & 0.390 & - & 0.167 \\
\hline
\end{tabular}

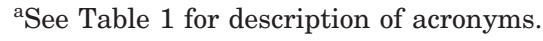


Table 5. Equations for predicting weight and percentage of retail product from carcass measurements ${ }^{\mathrm{a}}$

\begin{tabular}{|c|c|c|c|c|c|c|c|c|c|}
\hline \multirow[b]{2}{*}{$\begin{array}{l}\text { Dependent variable } \\
\text { and equation }\end{array}$} & \multirow[b]{2}{*}{$\mathrm{R}^{2}$} & \multirow[b]{2}{*}{ RMSE } & \multirow[b]{2}{*}{$\mathrm{C}_{\mathrm{p}}$} & \multicolumn{6}{|c|}{ Partial regression coefficients } \\
\hline & & & & Intercept & $\begin{array}{l}\text { ACFAT, } \\
\mathrm{cm}\end{array}$ & $\begin{array}{l}\mathrm{CKPH}, \\
\mathrm{cm}\end{array}$ & $\begin{array}{l}\text { CLMA, } \\
\mathrm{cm}^{2}\end{array}$ & $\begin{array}{c}\mathrm{HCW} \\
\mathrm{kg}\end{array}$ & MARB \\
\hline \multicolumn{10}{|l|}{ PRPRD } \\
\hline 10 & 0.57 & 2.76 & 164.65 & 75.07 & -6.727 & -1.372 & - & - & - \\
\hline 11 & 0.62 & 2.62 & 96.59 & 67.18 & -6.241 & -1.608 & 0.104 & - & - \\
\hline 12 & 0.65 & 2.52 & 49.71 & 68.83 & -5.472 & -1.417 & 0.165 & -0.023 & - \\
\hline 13 & 0.68 & 2.42 & 6.00 & 74.20 & -4.897 & -1.300 & 0.149 & -0.018 & -0.013 \\
\hline \multicolumn{10}{|l|}{ KGRPRD } \\
\hline 14 & 0.83 & 5.38 & 185.53 & 16.81 & -11.615 & - & - & 0.287 & - \\
\hline 15 & 0.85 & 4.95 & 76.45 & 3.79 & -9.418 & - & 0.308 & 0.249 & - \\
\hline 16 & 0.86 & 4.77 & 34.79 & 7.12 & -8.574 & -2.325 & 0.315 & 0.255 & - \\
\hline 17 & 0.87 & 4.64 & 6.00 & 15.60 & -7.668 & -2.141 & 0.289 & 0.262 & -0.020 \\
\hline
\end{tabular}

${ }^{\text {a}}$ See Table 1 for description of acronyms.

of the present study, Williams et al. (1997) and May et al. (2000) found ULMA to be a significant variable in live animal equations developed for prediction of both weight and percentage of retail product. Crouse et al. (1975) concluded that inclusion of longissimus muscle area may be useful to account for variation in cutability associated with breed groups due to a strong relationship between breed group means for cutability and longissimus muscle area. Researchers have found longissimus muscle area is a better indicator of weight than percentage of retail product (Hedrick et al., 1965; Abraham et al., 1968; Epley et al., 1970). When used as a single predictor in the current study, ULMA accounted for more of the variation in KGRPRD than PRPRD $\left(\mathrm{R}^{2}\right.$ $=0.38$ vs. 0.03 ).

Final live weight accounted for $66 \%$ of the initial variation in KGRPRD, with the remaining $16 \%$ of the variation accounted for by UFAT, ULMA, and URPFAT. In contrast, FWT was the last variable to enter stepwise prediction equations for PRPRD. Herring et al. (1994) and Williams et al. (1997) reported live weight was not a significant variable in prediction equations developed for percentage of retail product using live animal measures. Although FWT was significant $(P<$ 0.10 ) in the present study, comparison of Equations 5 and 6 reveal FWT resulted in minimal improvement in $\mathrm{R}^{2}$ and RMSE after UFAT, URPFAT, ULMA, and UBDWALL had been fit.

As a comparison, prediction equations for PRPRD and KGRPRD using carcass measurements are shown in Table 5. Equations including USDA yield grade variables resulted in $\mathrm{R}^{2}$ values of 0.65 and 0.86 for PRPRD and KGRPRD, respectively (Equations 12 and 16). Inclusion of MARB explained an additional $3 \%$ of the variation in PRPRD (Equation 13). When used alone, MARB was second only to ACFAT in explaining variation in PRPRD $\left(R^{2}=0.27\right)$, and was the second variable to be included in prediction equations using stepwise analysis (data not shown). This is in agreement with Kauffman et al. (1975), who reported marbling score to be superior to both kidney, pelvic, and heart fat and carcass weight in accounting for variation in percentage of fat-free muscle. Furthermore, Crouse and Dikeman (1976) reported correlations between marbling score and percentage of retail product of -0.38 within breeds and -0.48 across breed groups, and found marbling score to be useful as a predictor of percentage of retail product.

The best models using live animal measurements had similar $R^{2}$ values to models including carcass measurements currently used in USDA equations when predicting percentage (0.61, Equation 6 vs. 0.65 , Equation 12 ) or weight (0.84, Equation 9 vs. 0.86, Equation 16) of retail product. Hamlin et al. (1995), in a study using 180 steers from 11 sire-breed groups, reported $R^{2}$ values of 0.61 to 0.64 using live animal measures as predictors of retail yield, and concluded ultrasound-based equations were $10 \%$ less predictive of beef carcass retail yield than carcass-based equations. Faulkner et al. (1990), Bullock et al. (1991), Herring et al. (1994), and Williams et al. (1997) have demonstrated ultrasound measurements combined with other live animal variables to be as predictive as carcass measures for beef carcass composition. Herring et al. (1994) reported an $\mathrm{R}^{2}$ value of 0.34 using UFAT and visual fatness score to predict percentage of closely trimmed retail product. Using ultrasound and live measures similar to those in the present study, Williams et al. (1997) reported an $R^{2}$ of 0.32 for retail product yield $(0.32 \mathrm{~cm}$ fat trim). The higher $R^{2}$ values achieved in the present study for PRPRD ( 0.58 to 0.61 ) may be the result of more variation in cutability and carcass traits due to the sire breeds used in Cycle V compared with Herring et al. (1994) and Williams et al. (1997), who utilized populations of similar breed composition slaughtered at a pen average fat thickness endpoint. The high degree of accuracy with which ultrasound predicted carcass measurements also may have contributed to the small differences in $R^{2}$ values between live animal and carcass equations (Greiner et al., 2003). However, for retail product weight, Herring et al. (1994) and Williams et al. (1997) reported $R^{2}$ values of 0.82 to 0.87 using live animal 
measures, which are similar to those found in this study $\left(\mathrm{R}^{2}=0.78\right.$ to 0.84$)$.

As a single predictor, UFAT was equal to ACFAT in explaining initial variation in PRPRD $\left(\mathrm{R}^{2}=0.54\right.$ for both). In contrast, the $\mathrm{R}^{2}$ value for unadjusted carcass fat thickness used alone to predict PRPRD was 0.47. Due to the absence of disruptive processing factors, such as hide removal, fat thickness measured on the live animal using ultrasound may be as accurate as ACFAT for estimating the true amount of 12th-rib subcutaneous fat.

Despite a strong correlation between CLMA and ULMA ( $r=0.86)$, CLMA was more highly related to weight and percentage of retail product. Carcass longissimus muscle area accounted for $46 \%$ of the variation in KGRPRD compared with $37 \%$ for ULMA when fit alone. Similarly, CLMA explained $6.5 \%$ more of the variation in PRPRD than ULMA when each variable was used as a single predictor $\left(\mathrm{R}^{2}=0.093\right.$ vs. 0.028$)$. It appears from the present study that ultrasonic measurements of fat thickness may be more predictive than carcass measures for retail product yield, whereas longissimus muscle area measured on the carcass is more highly related to retail yield parameters than ultrasonic longissimus muscle area.

Equation 3 used ultrasound measurements of UFAT and ULMA along with FWT to predict PRPRD. The $\mathrm{R}^{2}$ value for this equation was lower than that reported for Equations 1 and 2, which include UFAT and URPFAT, or these two variables along with ULMA. It appears from the present study that two ultrasound fat measurements (UFAT and URPFAT) used in combination were more accurate and precise estimators of PRPRD than the combined traditional measures of UFAT, ULMA, and FWT. Inclusion of URPFAT with UFAT, ULMA, and FWT accounted for an additional $3 \%$ of the variation in PRPRD (Equation 3 vs. 4).

The higher $\mathrm{R}^{2}$ values reported for KGRPRD using carcass variables compared with live animal measurements are largely due to the difference in initial variation explained by HCW vs. FWT. As a single predictor, HCW explained 3\% more of the initial variation in KGRPRD than FWT. In fact, when HCW was used along with UFAT to predict weight of retail product, the resulting $\mathrm{R}^{2}$ value was the same (0.83) as that for Equation 14 which used HCW and ACFAT. Furthermore, substitution of FWT with HCW in Equations 7 through 9 increased coefficients of determination from 0.01 to 0.04 (data not shown). Therefore, differences in dressing percentage may account for a large portion of the differences in $R^{2}$ values between carcass and live animal equations for predicting KGRPRD.

\section{Implications}

This research indicates that live animal ultrasound measurements are useful predictors of retail yield. Alternative measurements of rump fat and body wall thickness are made possible with ultrasound technol- ogy, and these measurements enhanced the predictive capability of live animal-based equations for retail yield. Rump fat improved prediction equations for percentage of retail product when used along with live weight and traditional ultrasonic measurements of 12th-rib fat thickness and longissimus muscle area. The relative ease with which this measurement may be taken further justifies its inclusion. Although body wall thickness was found to be a significant variable in equations for retail yield, little additional variation was explained. Application of prediction equations for retail yield developed from ultrasound measurements warrant inclusion into genetic evaluation programs for carcass merit.

\section{Literature Cited}

Abraham, H. C., Z. L. Carpenter, G. T. King, and O. D. Butler. 1968. Relationships of carcass weight, conformation and carcass measurements and their use in predicting beef carcass cutability. J. Anim. Sci. 27:604-610.

Abraham, H. C., C. E. Murphy, H. R. Cross, G. C. Smith, and W. J. Franks Jr. 1980. Factors affecting beef carcass cutability: An evaluation of the USDA yield grades for beef. J. Anim. Sci. 50:841-851.

BIF. 1997. Proc. 29th Annu. Mtg. Beef Improvement Federation, Dickinson, ND.

Brungardt, V. H., and R. W. Bray. 1963. Estimate of retail yield of the four major cuts in the beef carcass. J. Anim. Sci. 22:177-182.

Bullock, K. D., J. K. Bertrand, L. L. Benyshek, S. E. Williams, and D. G. Lust. 1991. Comparison of real-time ultrasound and other live animal measures to carcass measures as predictors of beef cow energy stores. J. Anim. Sci. 69:3908-3916.

Cross, H. R., Z. L. Carpenter, and G. C. Smith. 1973. Equations for estimating boneless retail cut yields from beef carcasses. J. Anim. Sci. 37:1267-1272.

Crouse, J. D., and M. E. Dikeman. 1976. Determinates of retail product of carcass beef. J. Anim. Sci. 42:584-591.

Crouse, J. D., M. E. Dikeman, R. M. Koch, and C. E. Murphy. 1975. Evaluation of traits in the USDA yield grade equation for predicting beef carcass cutability in breed groups differing in growth and fattening characteristics. J. Anim. Sci. 41:548-553.

Duello, D. A. 1993. The use of real-time ultrasound measurements to predict composition and estimate genetic parameters of carcass traits in live beef cattle. Ph.D. Diss., Iowa State Univ., Ames.

Epley, R. J., H. B. Hedrick, W. C. Stringer, and D. P. Hutcheson. 1970. Prediction of weight and percent retail cuts of beef using five carcass measurements. J. Anim. Sci. 30:872-879.

Faulkner, D. B., D. F. Parrett, F. K. McKeith, and L. L. Berger. 1990. Prediction of fat cover and carcass composition from live and carcass measurements. J. Anim. Sci. 68:604-610.

Greiner, S. P., G. H. Rouse, D. E. Wilson, L. V. Cundiff, and T. L. Wheeler. 2003. The relationship between ultrasound measurements and carcass fat thickness and longissimus muscle area in beef cattle. J. Anim. Sci. 81:676-682.

Hamlin, K. E., R. D. Green, L. V. Cundiff, T. L. Wheeler, and M. E. Dikeman. 1995a. Real-time ultrasonic measurement of fat thickness and longissimus muscle area: II. Relationship between real-time ultrasound measures and carcass retail yield. J. Anim. Sci. 73:1725-1734.

Hedrick, H. B., J. C. Miller, G. B. Thompson, and R. R. Freitag. 1965. Factors affecting longissimus dorsi area and fat thickness of beef and relation between these measurements and retail yield. J. Anim. Sci. 24:333-337.

Herring, W. O., S. E. Williams, J. K. Bertrand, L. L. Benyshek, and D. C. Miller. 1994. Comparison of live and carcass equations predicting percentage of cutability, retail product weight, and trimmable fat in beef cattle. J. Anim. Sci. 72:1107-1118. 
Kauffman, R. G., M. E. Van Ess, R. A. Long, and D. M. Schaefer. 1975. Marbling: Its use in predicting beef carcass composition. J. Anim. Sci. 40:235-241.

MacNeil, M. D. 1983. Choice of a prediction equation and the use of the selected equation in subsequent experimentation. J. Anim. Sci. 57:1328-1336.

Mallows, C. L. 1973. Some comments on Cp. Technometrics 15:661.

May, S. G., W. L. Mies, J. W. Edwards, J. J. Harris, J. B. Morgan, R. P. Garrett, F. L. Williams, J. W. Wise, H. R. Cross, and J. W. Savell. 2000. Using live estimates and ultrasound measurements to predict beef carcass cutability. J. Anim. Sci. 78:1255-1261.

Miller, M. F., H. R. Cross, J. F. Baker and F. M. Beyers. 1988. Evaluation of live and carcass techniques for predicting beef carcass composition. Meat Sci. 23:111-129.

Perkins, T. L., R. D. Green, and M. F. Miller. 1992. Evaluation of alternative ultrasound measurement sites as estimators of yield grade factors in beef cattle. Proc. Western Sect. Am. Soc. Anim. Sci. 43:294-297.

Realini, C. E., R. E. Williams, T. D. Pringle, and J. K. Bertrand. 2001. Gluteus medius and rump fat depths as additional live animal ultrasound measurements for predicting retail product and trimmable fat in beef carcasses. J. Anim. Sci. 79-1378-1385.

Robinson, D. L., C. A. McDonald, K. Hammond, and J. W. Turner. 1992. Live animal measurement of carcass traits by ultrasound: Assessment and accuracy of sonographers. J. Anim. Sci. 70:1667-1676.

Wallace, M. A., J. R. Stouffer, and R. G. Westervelt. 1977. Relationships of ultrasonic and carcass measurements with retail yield in beef cattle. Livest. Prod. Sci. 4:153-164.

Wheeler, T. L., L. V. Cundiff, R. M. Koch, M. E. Dikeman, and J. D. Crouse. 1997. Characterization of biological types of steers (Cycle IV): Wholesale, subprimal, and retail product yields. J. Anim. Sci. 75:2389-2403.

Wheeler, T. L., L. V. Cundiff, S. D. Shackelford and M. Koohmaraie. 2001. Characterization of biological types of cattle (Cycle V): Carcass traits and longissimus palatability. J. Anim. Sci. 79:1209-1222.

Williams, R. E., J. K. Bertrand, S. E. Williams, and L. L. Benyshek. 1997. Biceps femoris and rump fat as additional ultrasound measurements for predicting retail product and trimmable fat in beef carcasses. J. Anim. Sci. 75:7-13. 